\title{
An Investigation of Surface Quality Cut by Abrasive Water Jet
}

\author{
Shijin Zhang*, Yuqiang Wu and Yanli Wang
}

College of Resources and Environmental Science, State Key Laboratory of Coal Mine Disaster Dynamics and Control, Key Laboratory for the Exploitation of Southwest Resources and Environmental Hazards Control Engineering of Ministry of Education, Chongqing University, Chongqing, 400030, P.R. China

\begin{abstract}
As abrasive water jet (AWJ) starts to be used in industry, especially in aerospace and automotive industries extensively, getting high quality surface has become a major requirement. Being a promising non-traditional cutting process, AWJ is holding several deficiencies, which limits its extensive applications dramatically. One of the deficiencies is striation marks presented on AWJ cutting surface. This paper investigated the triation formation mechanism systematically. This investigation leads to a conclusion that, striation can not be eliminated completely, however, by selecting proper paramters, smooth cutting surface can be achieved. Based on that conclusion, all parameters which might affect surface roughness have been explored, and an empirical model has been built and tested. With this empirical model, predicting surface quality becomes feasible and practical.
\end{abstract}

Keywords: Abrasive Water Jet (AWJ), striation formation mechanism, surface roughness, modeling.

\section{INTRODUCTION}

A typical abrasive water jet (AWJ) cutting head consists of several components, which include an orifice, a mixing chamber, a focusing tube and an abrasive feeding line. As shown in Fig. (1), when water is pressurized to a very high pressure (up to 600MPa) [1] by a pump and forced through a very small orifice $(0.1 \mathrm{~mm} \sim 0.5 \mathrm{~mm})$, a high velocity water jet beam is formed. This high velocity water jet beam can be used to cut soft materials such as rock, plastic and wood. When abrasive particles are added into the high velocity water jet beam, its cutting power is increased dramatically. In this case, water is no longer the cutting medium but the accelerating medium that transfers its momentum to abrasive particles which are entrained into a so-called mixing chamber from a hopper. This high energy abrasive stream can cut through almost all kinds of materials, including diamonds.

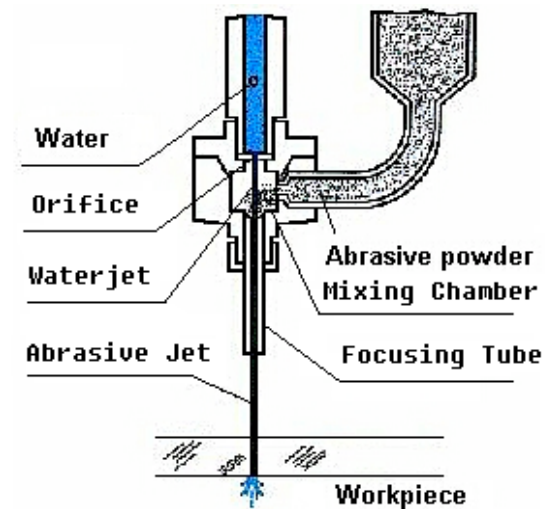

Fig. (1). Typical abrasive water-jet cutting head.

*Address correspondence to this author at the College of Resources and Environmental Science, Chongqing University, Chongqing, 400030, P.R. China; Tel: +86-023-65106122(office), +86-13648438470 (Mobile); Fax: +86-023-65106122;

E-mail: zhangshij@hotmail.com,shijinzhang@cqu.edu.cn
Known as an energy-concentrated, heat-easily-takenaway cutting tool, AWJ has many superior advantages inherently, comparing with other machine tools. These advantages can be summarized as following: (1) AWJ can be used to cut the materials that are very difficult to machine; (2) AWJ cutting process is a cold working process which generates no heat-affected zone (HAZ) that could compromise the structural integrity of a workpiece and form recast on finished parts; (3) AWJ cutting process induces very little mechanical stress that could cause surface/subsurface damage; (4) There is no direct contacting between tools and target materials. Because of the above advantages, the AWJ process is a very promising machining process.

With almost 30 years development, AWJ has been improved greatly in cutting precision and accuracy. Currently, for a typical cutting, as high as $\pm 0.025 \mathrm{~mm}$ locating tolerance has been achieved by using OMAX cutting system [2]. With a new component, tilting cutting head, installed on machine, taper has been removed completely [3]. The above new features lead to extensive applications of AWJ. While the usability of AWJ has been improved significantly, still some major geometric deficiencies, such as striation marks, limit AWJ's further application. This paper investigated the striation formation mechanism. Based on the striation formation mechanism investigation, parameters which might affect surface roughness have been explored and an empirical model for surface roughness has been built.

\section{THE STRIATION FORMATION MECHANISM INVESTIGATION}

As mentioned above, striation mark on AWJ cutting surface is one of the deficiencies which limit AWJ's applications dramatically. These striation marks, on the one hand, make the surface very rough. On the other hand, they lower the fatigue life of the target material. The striation phenomenon has been noticed and its formation mechanism has been studied through years. However, because of the com- 
plex of AWJ cutting process, different striation formation mechanisms have been provided by researchers. Guo et. al. owed the striation formation to the oscillating movements of the jet [4]. Chao [5], Monno [6], and Chen [7] regarded the vibrations during the cutting process as the resource for striation. Arola [8] and Zeng [9] considered that the reason for striation marks to be formed on AWJ cutting surfaces is because of the jet kinetic energy decreasing with the increasing of the cutting depth as. Orbanic and Junkar used two analogies from the nature and technical world to describe the striation formation mechanism [10]. In a summary, according to researchers, striation could be caused by oscillating movement of the jet, vibration of the jet and abrasive, and lower kinetic energy of the jet in deeper cutting depth. In order to reveal the real reason of striation formation, a series of well-known visualization experiments have been carried out in this paper.

\subsection{Jet Vibration Test}

As mentioned above, one of the reasons which might cause striation formation is the vibration of the jet, no matter the vibration comes from the motion system of the machine or from the jet itself. Without a doubt, the motion of the mechanical system would cause vibration, and the vibration would affect the cutting surface. However, the modern design of the motion system has decreased its mechanical effect to be ignorable, especially when the cutting speed is low. Therefore, this paper won't focus on vibration investigation caused by motion system.

Another resource which might cause vibration is jet itself. In order to verify that, a series of jet vibration tests have been carried out. In these tests, a high-speed camera which can take up to 1000 frames per second has been used to film the jet vibration. With this high filming rate, details of the jet vibration could be recorded. In this test, the filming rate is selected as 240 frames per second, by which the recording time is much longer since the memory of the camera is limited. The experimental setup is shown in Fig. (2). The camera has been positioned around $300 \mathrm{~mm}$ away from the cutting head. In order to get good visibility, two lights have been positioned beside the camera.

The operating parameters of jet vibration tests are listed in Table 1. And part of the recording results is shown in Fig. (3).

Table 1. Operating Parameters of Jet Vibration Test

\begin{tabular}{|c|c|}
\hline Water Pressure $[\mathrm{MPa}]$ & 350 \\
\hline Orifice Diameter $[\mathrm{mm}]$ & 0.25 \\
\hline Focusing Tube Diameter $[\mathrm{mm}]$ & 0.51 \\
\hline Abrasive Type & SinoGarnet \\
\hline Abrasive Size $[\mathrm{mesh}]$ & $120 \mathrm{AA}$ \\
\hline Abrasive Flowrate $[\mathrm{g} / \mathrm{s}]$ & 8.4 \\
\hline
\end{tabular}

Fig. (3) shows two adjacent images taken by the highspeed camera. The interval between these two frames is 0.0042 second. As Fig. (3) shown, the jet on the right is much fatter than the left one, which means that vibration does exist in jet. Instead of keeping the same expansion angle during jet shooting process, the expansion angle of the jet changes periodically. Further investigation shows that, same vibration trend also presented in pure water jet. Although the images verifies that the jet vibration does exist, the frequency of the jet vibration is much higher comparing

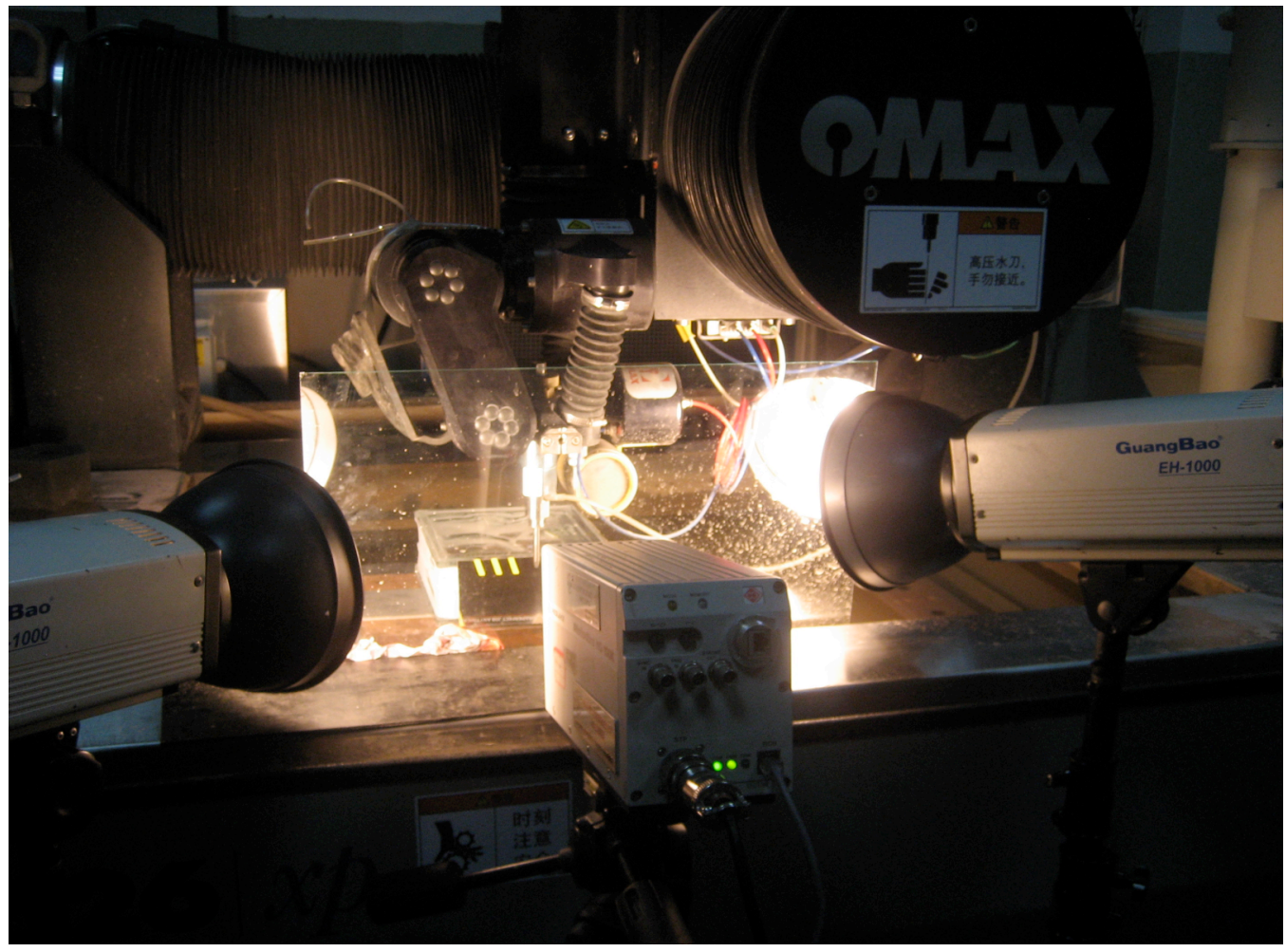

Fig. (2). Experimental setup for jet vibration visualization test. 


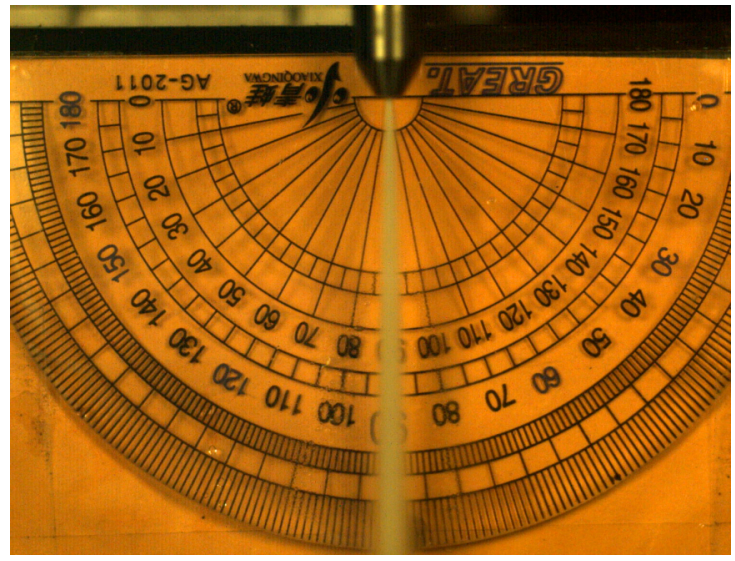

(a)

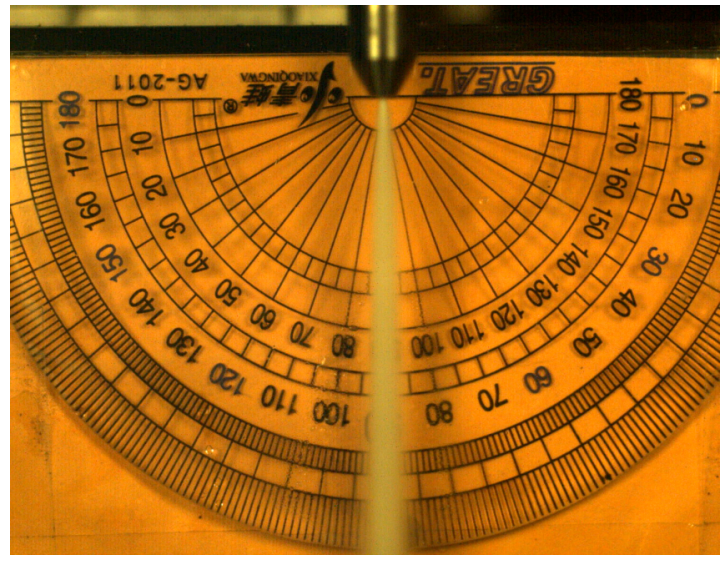

(b)

Fig. (3). Jet vibration process monitoring.

with frequency of striation marks on AWJ cutting surfaces. Therefore, the vibration of jet is not the major reason which cause striation marks on AWJ cutting surfaces.

\subsection{Jet Cutting Test}

To further examining the striation formation mechanism, a series of transparent material cutting tests have been carried out. The setup of the cutting tests is shown in Fig. (4), and the operating parameters are listed in Table 2.

\section{Table 2. Operating Parameters of Jet Cutting Test}

\begin{tabular}{|c|c|}
\hline Water Pressure $[\mathrm{MPa}]$ & 315 \\
\hline Orifice Diameter $[\mathrm{mm}]$ & 0.35 \\
\hline Focusing Tube Diameter $[\mathrm{mm}]$ & 0.89 \\
\hline Abrasive Type & SinoGarnet \\
\hline Abrasive Size $[\mathrm{mesh}]$ & 100 \\
\hline Abrasive Flowrate $[\mathrm{g} / \mathrm{s}]$ & 6 \\
\hline Cutting speed $[\mathrm{mm} / \mathrm{s}]$ & 3.2 \\
\hline Target material & glass \\
\hline Target material thickness $[\mathrm{mm}]$ & 40 \\
\hline
\end{tabular}

Fig. (5) shows the initial cutting stage. In this stage, AWJ only cut into part of the whole thickness of the target material. The four images in Fig. (5) are taken with a 240 frames/s filming rate. Under this high filming rate, no any cutting steps are presented in the cutting process. As the cutting goes further, as shown in Fig. (6), step is presented in Fig. (6a). Fig. (6b) shows that the step is cut away shortly after it is formed. According to the above images, in initial cutting stage, the jet kinetic energy is high enough to cut through target material directly. However, as the cutting depth increases, the jet kinetic energy decreases with the increase of cutting depth. As a result, target material can't be cut away directly and a step is formed. The step can be removed by the secondary and tertiary impacts of the deflected jet as long as the accumulated jet energy is high enough. Further tests with different cutting speeds also have demonstrated that. However, in step removing process, though steps can be removed, the process is an unstable cutting process, in which the material removed is out of control. Therefore, rough cutting surface is expected during this process. To get smooth cutting surface, direct cutting process is needed. This can be realized by slowing down the cutting speed, by which more abrasive particles impact on

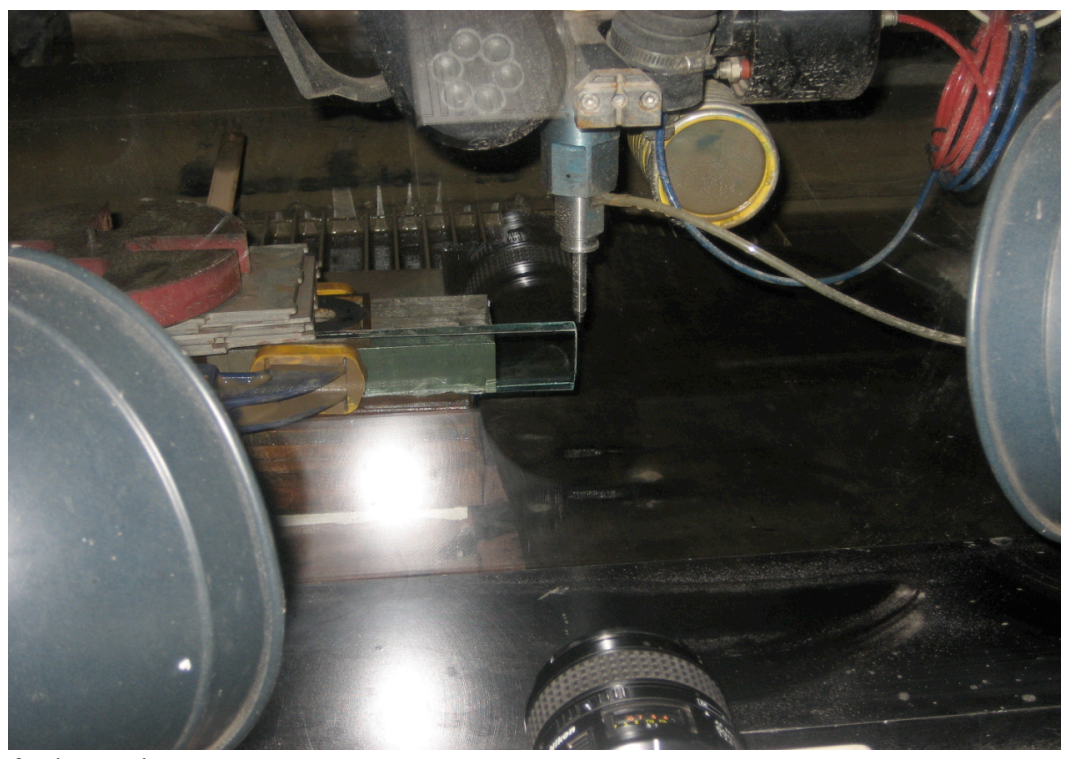

Fig. (4). Experimental setup for jet cutting process. 


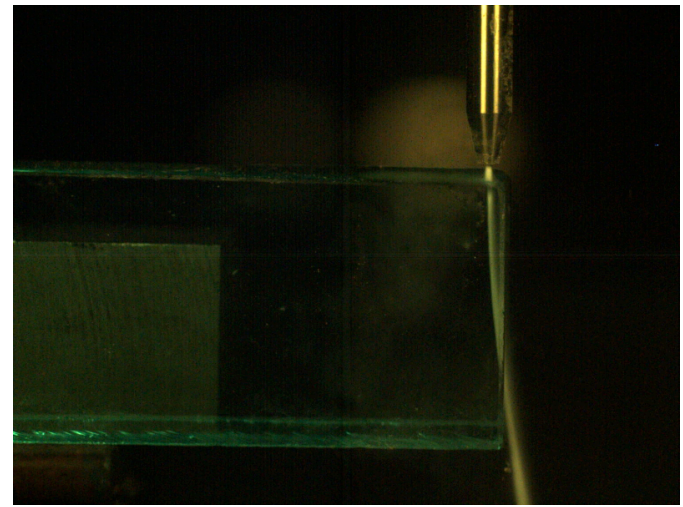

(a)

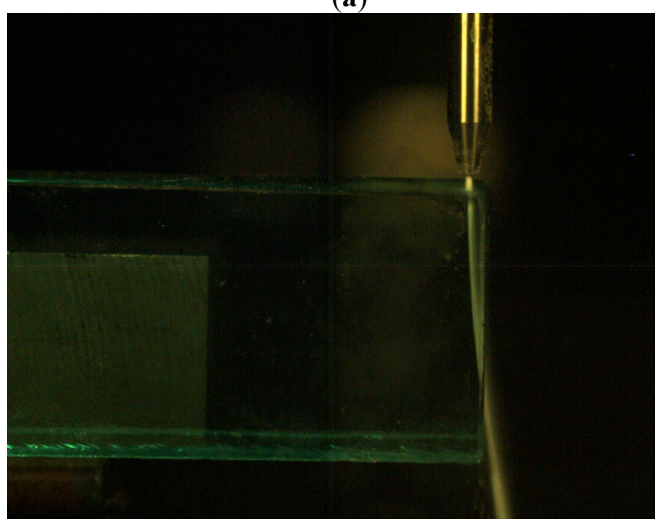

(c)

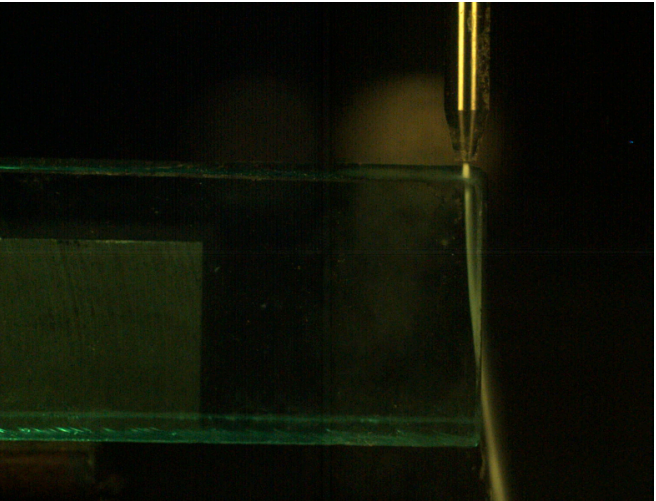

(b)

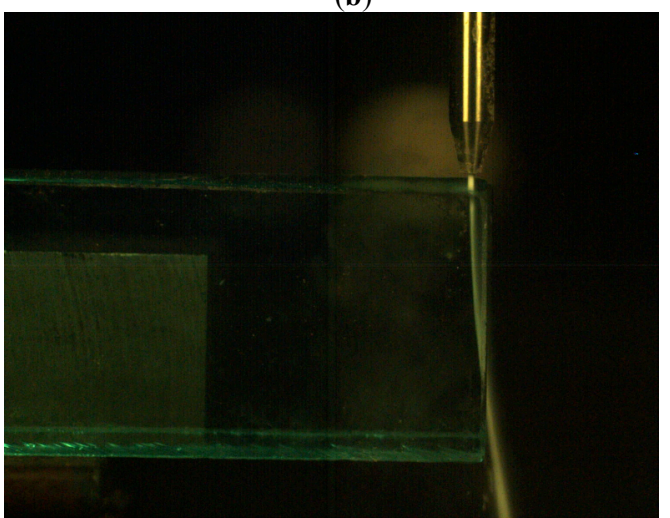

(d)

Fig. (5). AWJ glass cutting process monitoring (initial stage).
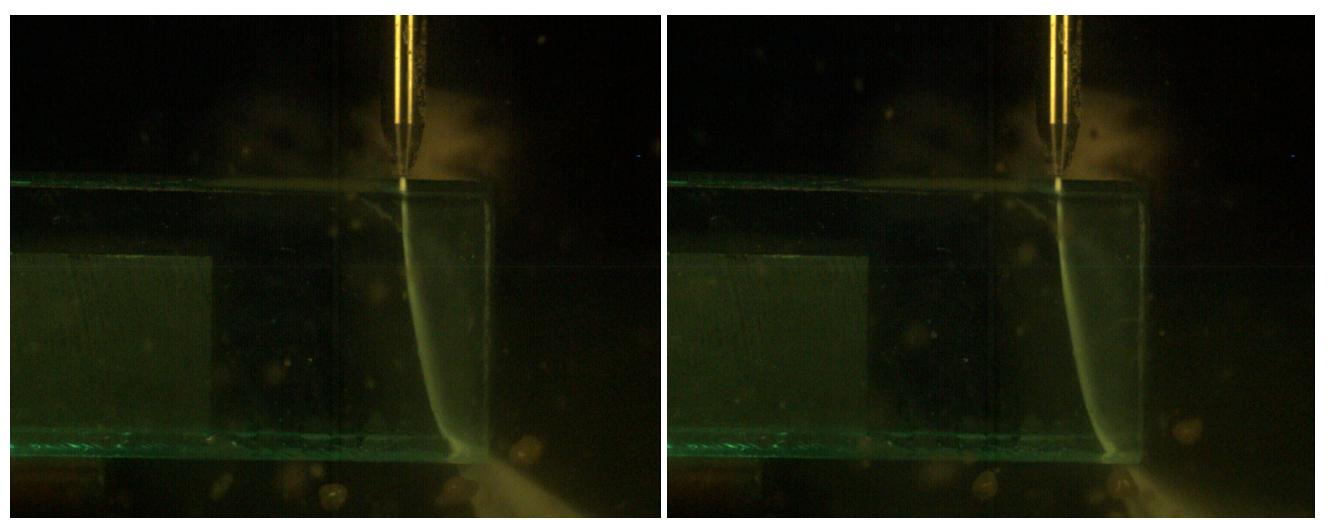

(a)

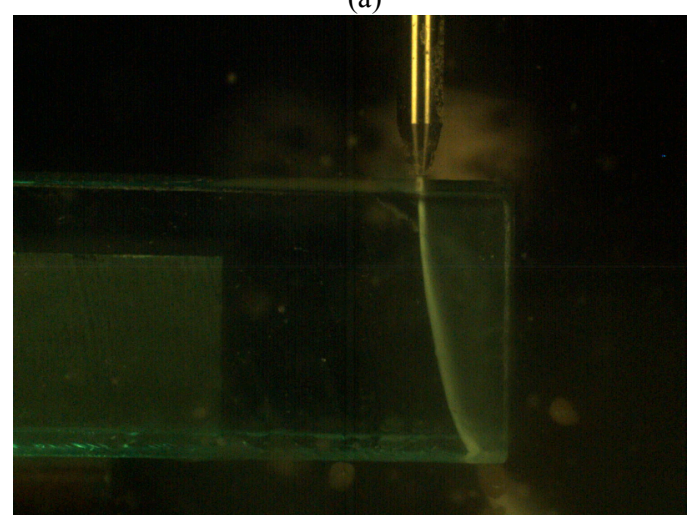

(b)

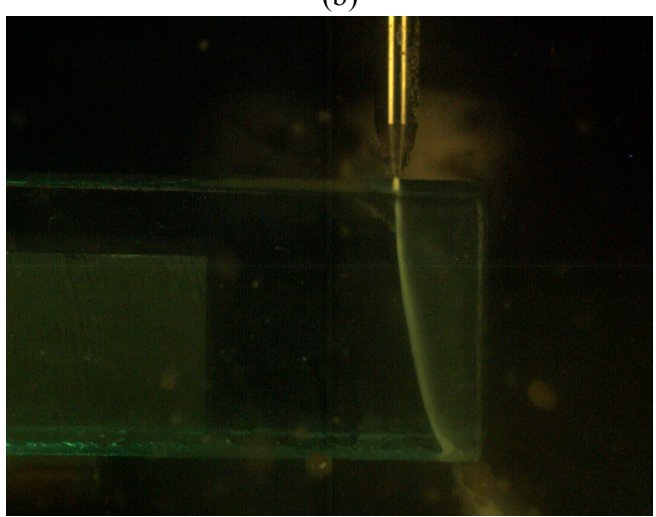

(c)

(d)

Fig. (6). AWJ glass cutting process monitoring (developed stage).

the same spot to finish the direct cutting process. This method isn't feasible for very thick material, in which abrasive particles lose their energy when they travel to a certain depth. 


\section{SURFACE ROUGHNESS INVESTIGATION}

As mentioned above, striation marks, on the one hand, make most surfaces too rough to be accepted, which limit AWJ's applications in many fields, especially in aerospace industries. On the other hand, they also decrease the fatigue life of the target material dramatically. Theoretically, it is impossible to eliminate the striation marks on the cutting surface. However, by selecting proper parameters, the surface quality could be controlled properly.

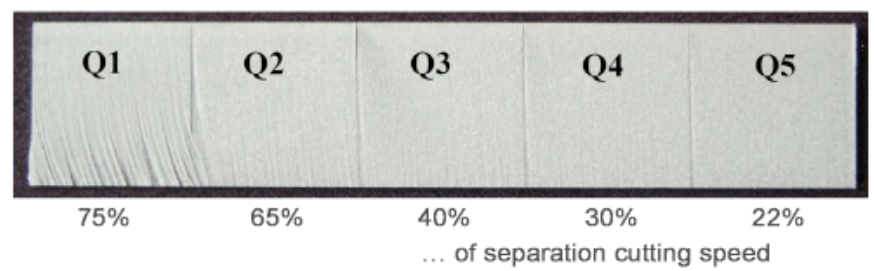

Fig. (7). Different cutting speeds lead to different surface quality.

As shown in Fig. (7), by slowing down cutting speed, very smooth surface can be achieved. Many researchers have performed systematic studies on parameters which affect surface roughness. Momber et al. [11] reported that increasing in water pressure generally improves the surface quality; Singh et al. [12] and Blickwedel et al. [13] observed that the surface roughness changes dramatically at high traverse rates, but at comparatively low traverse rates, the roughness showed almost stable; Guo [14] noticed that the roughness decreased with an increase in the abrasive flowrate. Based on those prior efforts, predicting the parameters which affect surface roughness would appear to be both feasible and practical. However, knowing the influential parameters is not enough when applying this technology into higher tolerance cutting. To increase the precision and accuracy during cutting process, predicting what roughness would be expected with selected parameters accurately is very important. This section investigated how the parameters affect surface roughness. Based on the investigation, an empirical model for surface roughness prediction has been built.

\subsection{Target Material Selection}

As mentioned above, one of the most important advantages for AWJ is easily to cut material which is difficult to machine traditionally. Titanium alloy, Ti-6Al-4V, has been known for a while due to their superior combination of metallurgical and physical properties which include high strength-to-weight ratios, low densities, excellent corrosion resistance, excellent erosion resistance and low modulus of elasticity. Because of their excellent properties, industrial applications for titanium alloys include aircraft, aeroengines, biomedical devices, and components in chemical processing equipment [15]. However, as a very chemically reactive material which has a tendency to weld to the cutting tool and lead to premature tool failure during machining process, titanium is classified as a material which is very difficult to machine [16]. Additionally, titanium has low thermal conductivity which increases the temperature at toolworkpiece interface thus, affecting the tool life adversely. Therefore, machining of titanium alloys poses a serious challenge for industry, and there is a strong need to develop an effective method for machining titanium alloys. To demonstrate AWJ's potential in machining material which is difficult to machine traditionally, Ti-6Al4V has been selected as target material.

\subsection{Experimental Investigation}

In order to investigate the parameters which affect surface roughness, a series of experiments were carried out. In these experiments, an abrasive metering and delivery system through which the AFR could be adjusted freely in the range from $0 \mathrm{~kg} / \mathrm{min}$ to $1.5 \mathrm{~kg} / \mathrm{min}$ was used. Previous experiments [17] have worked out optimum AFR at highest cutting speed under different cutting conditions. Therefore, optimum AFR was used as AFR corresponding to each set of cutting conditions. During this work, only 80 mesh Barton garnet are used since this size is a very common size. A nozzle design with nozzle pairs of 0.25:0.76 $\mathrm{mm}$ nozzle combination and $0.35: 1.05 \mathrm{~mm}$ nozzle combination are used in these experiments. Since titanium alloy Ti6A14V has been used extensively in aerospace industry, all experiments were carried on this target material. Note that it will change in value for differing conditions.

\subsubsection{Experimental Conditions}

Tests were carried out as a full factorial experiment, with the levels of the test parameters defined as,

Water pressure: $210 / 280 / 350 / 420 \mathrm{MPa}$

Nozzle combination: $0.25: 0.76 \mathrm{~mm}$ and $0.35: 1.05 \mathrm{~mm}$ respectively

Abrasive: 80 mesh Barton garnet

Cutting quality level index: $2 / 3 / 4 / 5$ respectively

Target material: Ti6Al4V, $7.0 \mathrm{~mm} / 13.2 \mathrm{~mm} / 20.32 \mathrm{~mm}$ thick respectively

Standoff distance: $1 \mathrm{~mm}$

Abrasive flowrate was calculated by the previously built model [18] under each set of cutting conditions:

$m_{A}=0.612 P^{0.3432} d_{0}^{1.5801} d_{f}^{0.9435}$

where,

$m_{A}$ : Optimum abrasive flowrate at highest cutting speed $(\mathrm{kg} / \mathrm{min})$;

$P$ : Water pressure (Mpa);

$d_{0}$ : Orifice diameter $(\mathrm{mm})$;

$d_{f}$ : Focusing tube diameter (mm);

Cutting speed was gotten from Zeng's model [19] as following:

$u=\left(\frac{f_{a} N_{m} P_{w}^{1.594} d_{0}^{1.374} M_{a}^{0.343}}{C q h d_{m}^{0.618}}\right)^{1.15}$

where,

$u$ : the cutting speed $(\mathrm{mm} / \mathrm{min}$ or inch $/ \mathrm{min})$

$f_{a}$ : abrasive factor (1 for garnet)

$N_{m}$ : machinability number (108 for titanium alloy)

$P_{w}:$ water pressure (Mpa or kps) 
$d_{0}:$ orifice diameter ( $\mathrm{mm}$ or inch)

$M_{a}:$ abrasive flowrate $(\mathrm{g} / \mathrm{min}$ or $1 \mathrm{~b} / \mathrm{min})$

$q$ : quality level index

$h$ : workpiece thickness (mm or inch)

$d_{m}$ : mixing tube diameter ( $\mathrm{mm}$ or inch)

$C$ : system constant (788 for Metric units or 163 for English units)

Based on above cutting conditions, optimum AFR can be calculated as shown in Table 3:

Table 3. Optimum Abrasive Flowrate Affected by Cutting Parameters

\begin{tabular}{|c|c|c|c|}
\hline \multirow{2}{*}{$\begin{array}{c}\text { Orifice } \\
\text { Diameter (mm) }\end{array}$} & $\begin{array}{c}\text { Mixing Tube } \\
\text { Diameter (mm) }\end{array}$ & $\begin{array}{c}\text { Pressure } \\
\text { (Mpa) }\end{array}$ & $\begin{array}{c}\text { Optimum AFR } \\
\text { (kg/min) }\end{array}$ \\
\hline \hline \multirow{3}{*}{0.25} & \multirow{3}{*}{0.76} & 210 & 0.33 \\
\cline { 3 - 4 } & & 280 & 0.37 \\
\cline { 3 - 4 } & & 350 & 0.39 \\
\cline { 3 - 4 } & \multirow{3}{*}{0.35} & 420 & 0.42 \\
\hline \multirow{2}{*}{1.05} & 210 & 0.76 \\
\cline { 3 - 4 } & & 280 & 0.84 \\
\cline { 3 - 4 } & & 350 & 0.91 \\
\cline { 3 - 4 } & & 420 & 0.97 \\
\hline
\end{tabular}

\subsubsection{Experimental Procedure}

In order to investigate how each parameter affects surface roughness, a series of $50 \mathrm{~mm}$ long, $5 \mathrm{~mm}$ thick blocks have been cut by setting different parameters. After cutting, surface roughness for each piece of block has been measured. A typical surface cut by AWJ can be categorized as a smooth upper zone and a rough lower zone. Therefore, it is reasonable to investigate both top side and bottom side surface roughness at the same time. In this experiment, an SJ-201P surface roughness tester has been used and the measurement zone is located at $1 \mathrm{~mm}$ away from top edge and bottom edge respectively. The cutoff length for the measurement is $2.5 \mathrm{~mm}$.

\subsubsection{Test Results and Discussion}

As mentioned above, in order to find out how cutting parameters affects Ti6Al4V cutting surface roughness, different cutting parameters, such as water pressure, cutting level index, nozzle combination, etc., have been tested, and surface roughness has been measured.

Theoretically, cutting speed is a major factor which affects surface roughness. The lower the cutting speed, the more abrasive particles would work on the same spot and make it smoother.

As shown in Figs. (8-13), under each set of cutting conditions (fixed nozzle combination and target material thickness), both top side and bottom side surface roughness is affected by cutting speed. Higher cutting speed corresponds to rougher surface. Additionally, surface roughness on both top side and bottom side are linearly correlated to cutting speed though on bottom side the correlation coefficient is much higher than that on top side. Although all other cutting parameters, such as water pressure, quality level index, target material thickness, etc., are related to cutting speed, how those parameters affect surface roughness is still unknown. It is necessary to investigate those parameters.

Surface Roughness Affected by Cutting Speed

(0.35:1.05mm nozzle combination, $20.32 \mathrm{~mm}$ thick material)

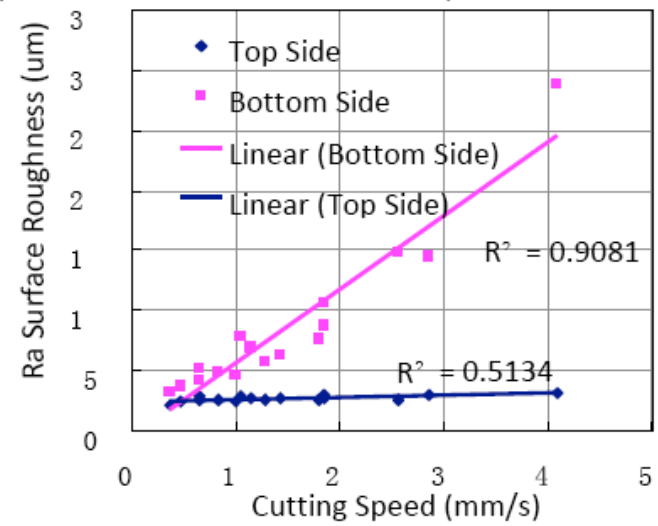

Fig. (8). Surface roughness affected by cutting speed $(20.32 \mathrm{~mm}$ thick Ti6Al4V cut by $0.35: 1.05 \mathrm{~mm}$ nozzle combination).

Surface Roughness Affected by Cutting Speed (0.35:1.05mm nozzle combination, $13.2 \mathrm{~mm}$ thick material)

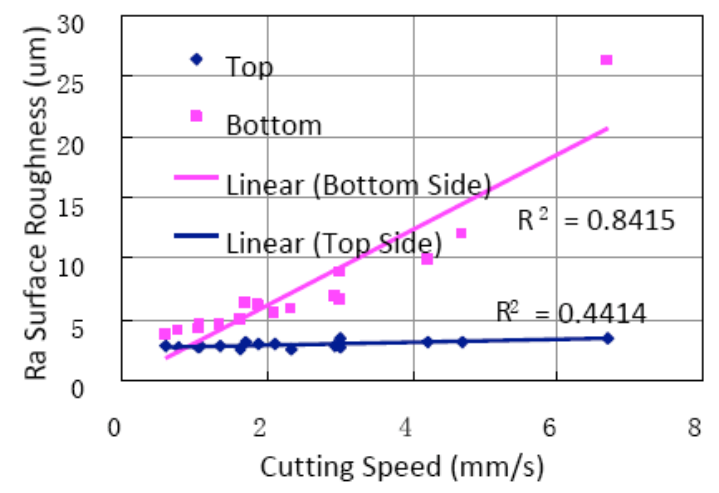

Fig. (9). Surface roughness affected by cutting speed $(13.2 \mathrm{~mm}$ thick Ti6Al4V cut by $0.35: 1.05 \mathrm{~mm}$ nozzle combination).

Surface Roughness Affected by Cutting (0.35:1.05mm nozzle combination, $7.0 \mathrm{~mm}$ thick material)

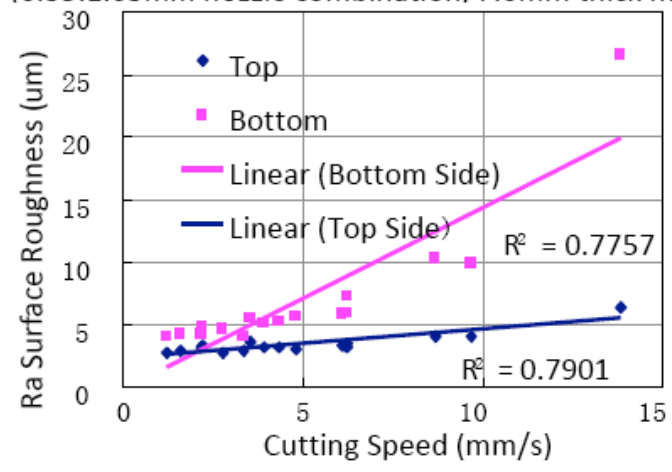

Fig. (10). Surface roughness affected by cutting speed $(7.0 \mathrm{~mm}$ thick Ti6Al4V cut by $0.35: 1.05 \mathrm{~mm}$ nozzle combination). 
Surface Roughness Affected by Cutting Speed

(0.25:0.76mm nozzle combination, $20.32 \mathrm{~mm}$ material)

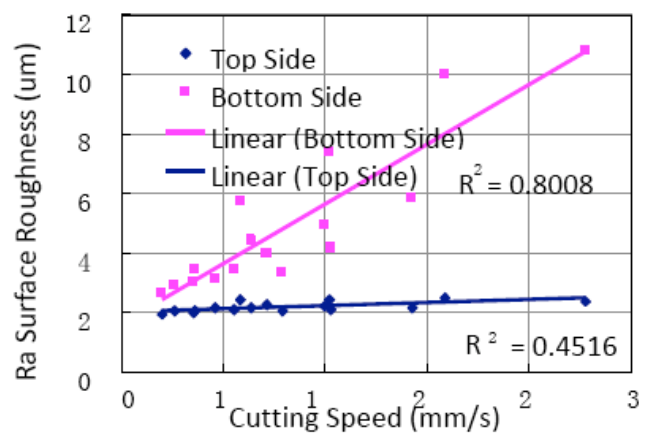

Fig. (11). Surface roughness affected by cutting speed $(20.32 \mathrm{~mm}$ thick Ti6A14V cut by $0.25: 0.76 \mathrm{~mm}$ nozzle combination).

Surface Roughness Affected by Cutting (0.25:0.76mm nozzle combination, $13.2 \mathrm{~mm}$ thick material)

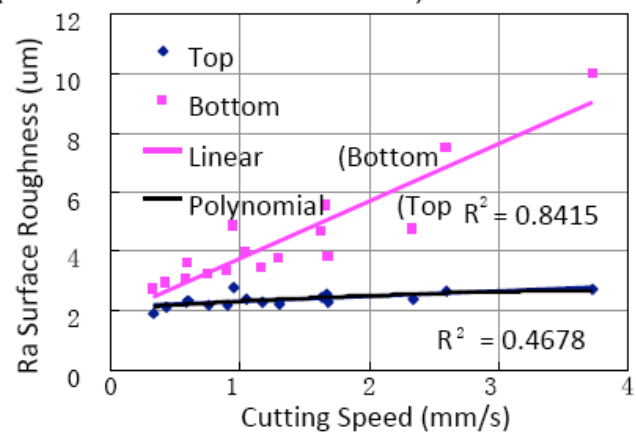

Fig. (12). Surface roughness affected by cutting speed $(13.2 \mathrm{~mm}$ thick Ti6Al4V cut by $0.25: 0.76 \mathrm{~mm}$ nozzle combination).
Surface Roughness Affected by Cutting

(0.25:0.76mm nozzle combination, $7.0 \mathrm{~mm}$ thick material)

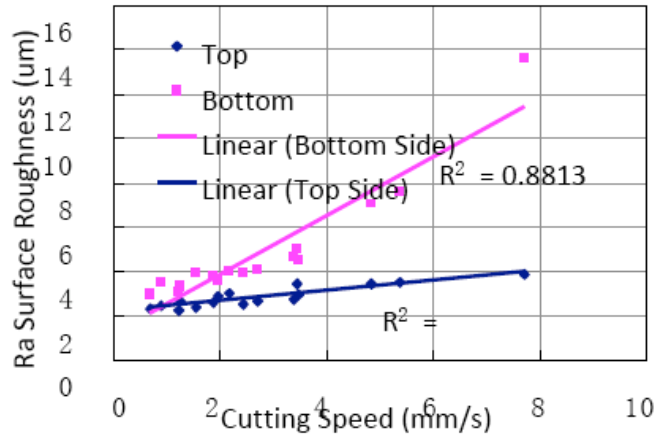

Fig. (13). Surface roughness affected by cutting speed $(7.0 \mathrm{~mm}$ thick Ti6Al4V cut by $0.25: 0.76 \mathrm{~mm}$ nozzle combination).

From Fig. (14) and 15, on top side, surface roughness $\mathrm{Ra}$ is in the range of 2 to $5 \mu \mathrm{m}$, but on bottom side, Ra could be as low as $3 \mu \mathrm{m}$ and as high as $30 \mu \mathrm{m}$. Also as shown in Fig. (14), for the same thick target material, though cut by different nozzle combinations, the surface roughness to cutting speed ratios almost have the same trend. However, different target material thicknesses show different surface roughness to cutting speed trends. Seems material thickness is a major factor which affects surface roughness. Fig. (15) shows that surface roughness to cutting speed ratio trend is very close when the target material thickness keeps the same, which strengthens the conclusion that material thickness affects surface roughness. But, from Fig. (15), nozzle combination is also a factor which affects surface roughness.

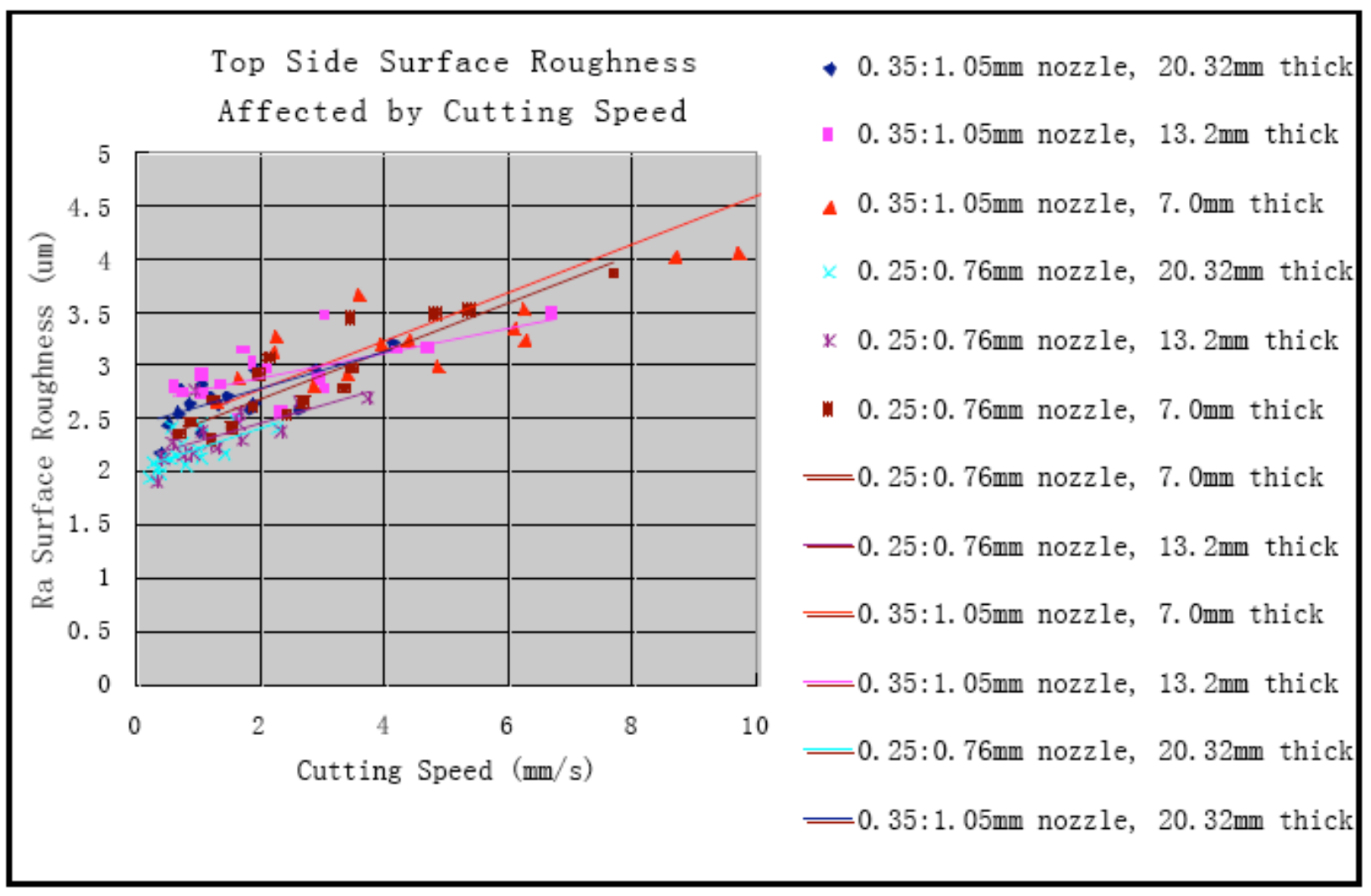

Fig. (14). Top Side surface roughness affected by cutting speed. 


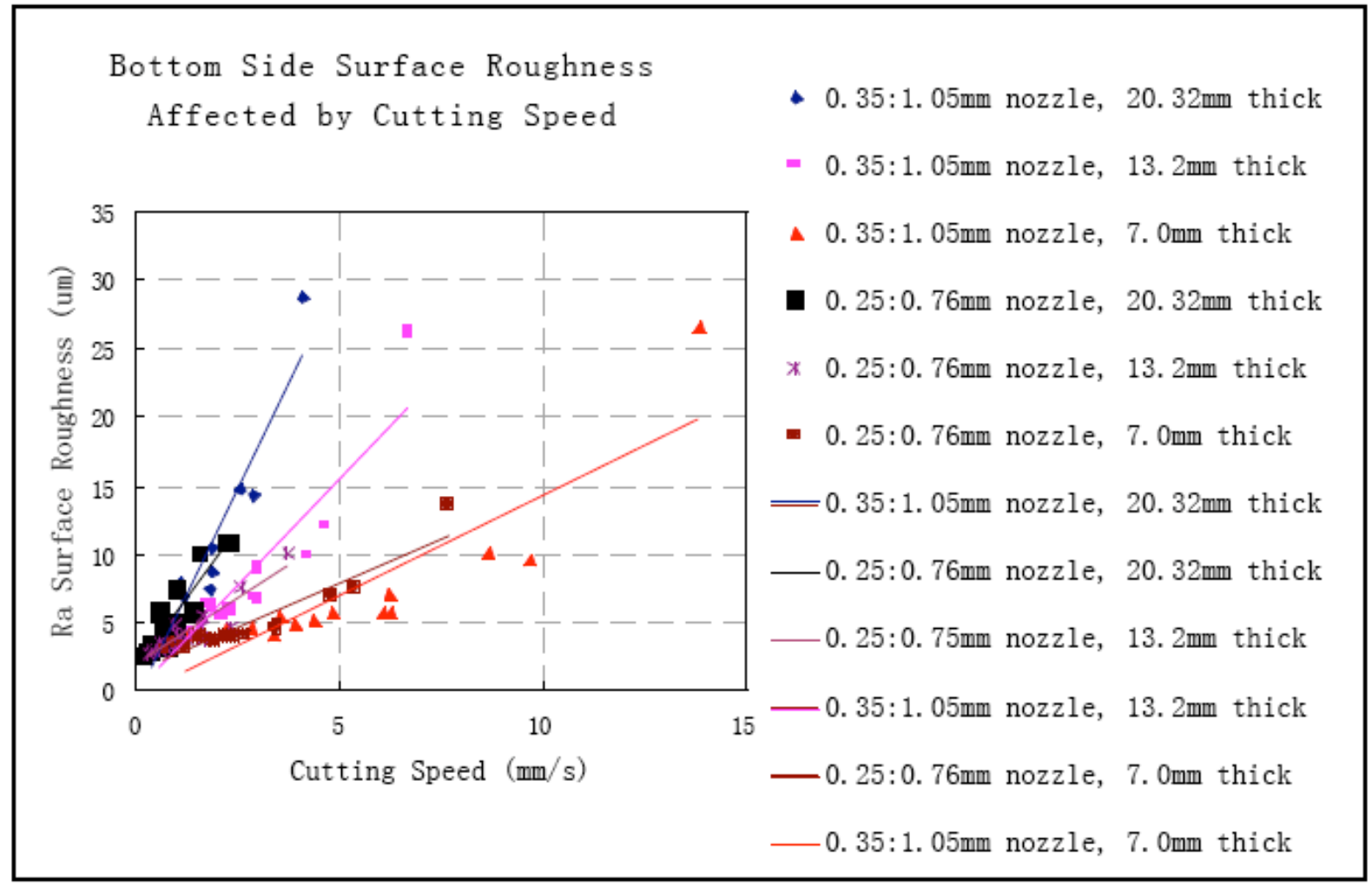

Fig. (15). Bottom Side surface roughness affected by cutting speed.

In order to further study how each parameter affects surface roughness, more analysis has been carried out.

Top Side Surface Roughness Affected by Water (0.35:1.05mm nozzle combination, $20.32 \mathrm{~mm}$ thick material)

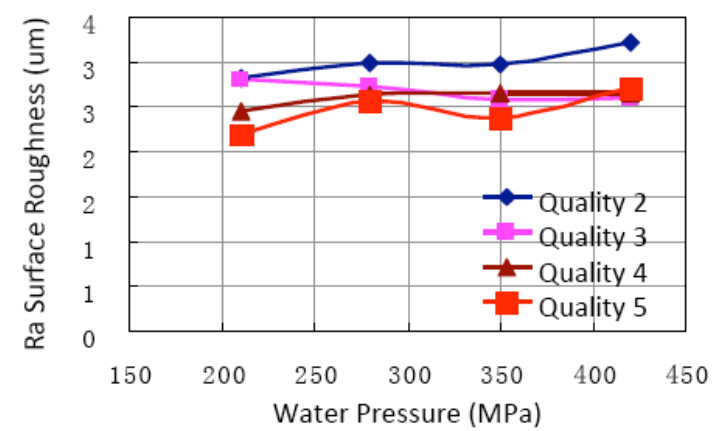

Fig. (16). Top side surface roughness affected by water pressure (0.35:1.05mm nozzle combination, $20.32 \mathrm{~mm}$ thick material).

Bottom Side Surface Roughness Affected by Water (0.35:1.05mm nozzle combination, $20.32 \mathrm{~mm}$ thick material)

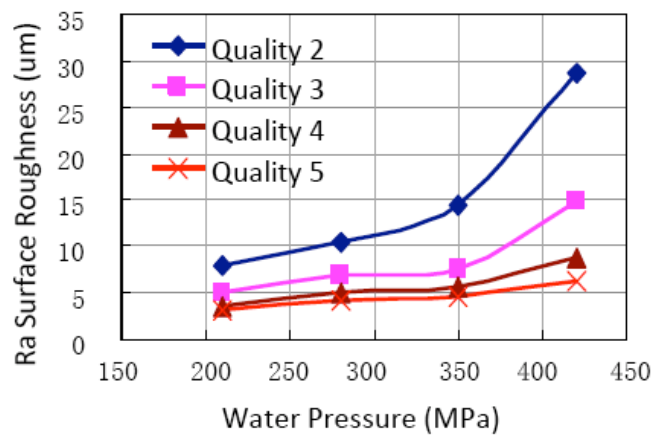

Fig. (17). Bottom side surface roughness affected by water pressure (0.35:1.05mm nozzle combination, $20.32 \mathrm{~mm}$ thick material).
As shown in Figs. (16 and 17), water pressure is one of the factors which affect surface roughness on both top side and bottom side. Under the same cutting conditions, including same quality level index, abrasive type and mesh, nozzle combination, target material thickness, increasing water pressure would roughen cutting surface, especially on bottom surface. Figs. (16 and 17) also show water pressure has different influences on surface roughness when quality level indexes are different.

As shown in Figs. (18 and 19), quality level index also affects surface roughness on both top side and bottom side. When other parameters are fixed, higher quality level index corresponds to lower surface roughness.

Top Side Surface Roughness Affected by Quality Level Index (0.35:1.05mm nozzle combination, $20.32 \mathrm{~mm}$ thick material)

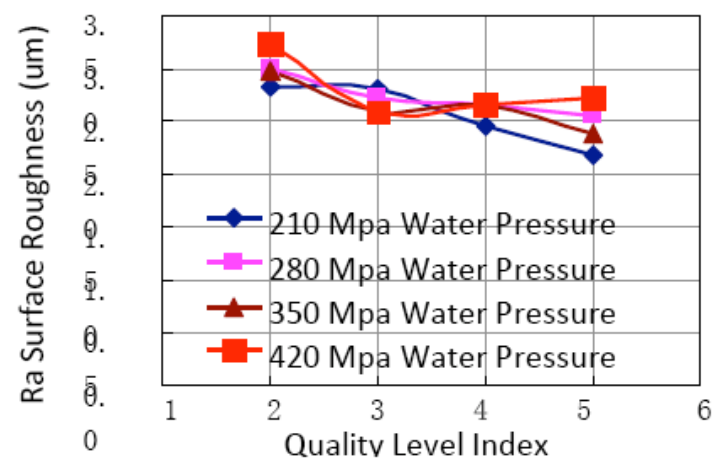

Fig. (18). Top side surface roughness affected by quality level index (0.35:1.05mm nozzle combination, $20.32 \mathrm{~mm}$ thick material). 
Bottom Side Surface Roughness Affected by Quality Level Index (0.35:1.05 mm nozzle combination, $20.32 \mathrm{~mm}$ thick material)

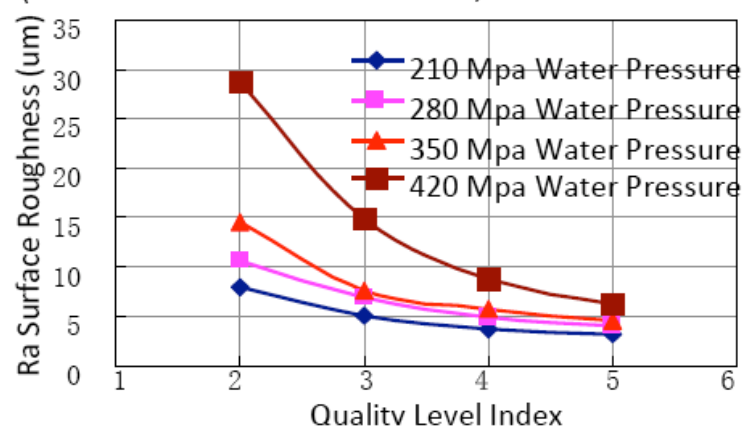

Fig. (19). Bottom side surface roughness affected by quality level index (0.35:1.05mm nozzle combination, $20.32 \mathrm{~mm}$ thick material).

From Figs. (20 and 21), under same cutting conditions, 0.35:1.05mm nozzle combination generates higher surface roughness than $0.25: 0.76 \mathrm{~mm}$ nozzle combination does. Possible reason for that is bigger nozzle combination orresponds to higher cutting speed.

Top Side Surface Roughness Affected by Combination

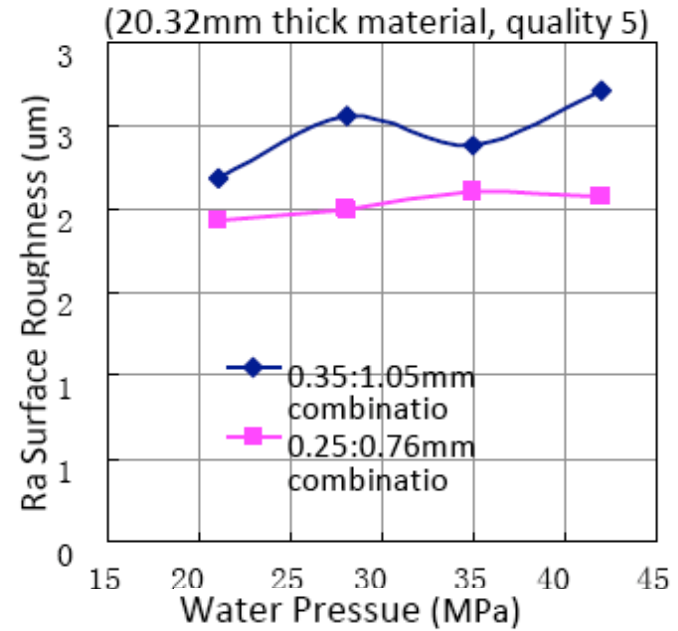

Fig. (20). Top side surface roughness affected by nozzle combination (20.32 $\mathrm{mm}$ thick material, quality 5$)$.

Bottom Side Surface Roughness Affected bv Combination (20.32 $\mathrm{mm}$ thick material, quality

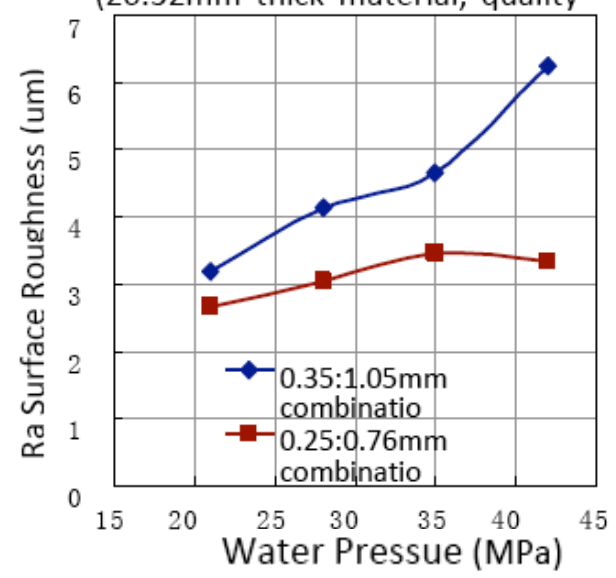

Fig. (21). Bottom side surface roughness affected by nozzle combination (20.32 $\mathrm{mm}$ thick material, quality 5$)$.
As shown in Figs. (22 and 23), surface roughness is affected by target material thickness. When other parameters are fixed, rougher surface has been generated for thicker target material.

Top Side Surface Roughness Affected by Material Thickness (0.35:1.05mm nozzle combination, quality 2$)$

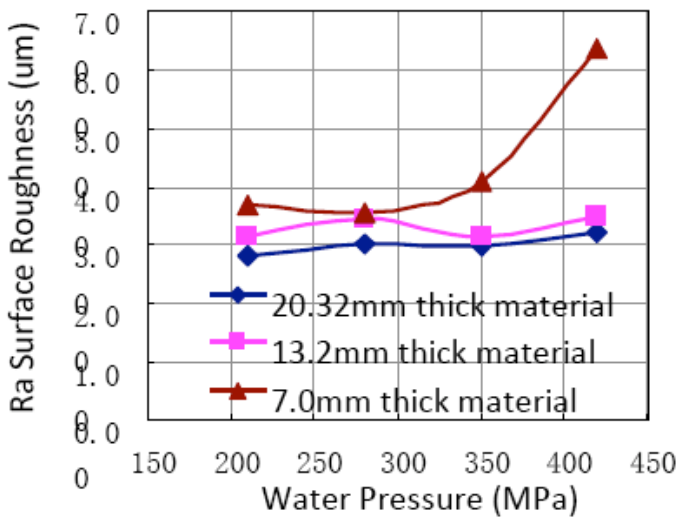

Fig. (22). Top side surface roughness affected by material thickness (0.35:1.05mm nozzle combination, quality 2$)$.

Surface Roughness Affected by Material (0.35:1.05mm nozzle combination, quality 2 )

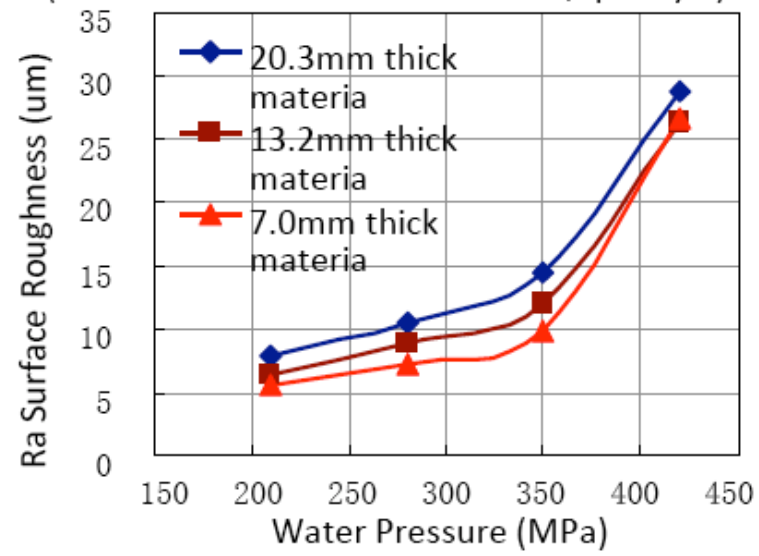

Fig. (23). Bottom side surface roughness affected by material thickness $(0.35: 1.05 \mathrm{~mm}$ nozzle combination, quality 2$)$.

\subsection{Model Development}

Based on the above experiments, surface roughness on both top side and bottom side could be expressed as a linear function of cutting speed. So, it is reasonable to have the following equation,

$R_{a}=a u+b$

Where,

$R_{a}$ : surface roughness $(\mu m)$;

$a$ : constant;

$b$ : constant.

If the cutting speed is zero, no cutting occurs, and no surface roughness exists. In order to make the analysis simple, it is reasonable to assume the straight line passes through zero point and constant $b$ can be ignored. Therefore, it is reasonable to have the following expression,

$R a=a u$ 
Since,

$$
u=\left(\frac{f_{a} N_{m} P_{w}^{1.594} d_{0}^{1.374} M_{a}^{0.343}}{C q h d_{m}^{0.618}}\right)^{1.15}
$$

Therefore,

$$
R a=a u=a\left(\frac{f_{a} N_{m} P_{w}^{1.594} d_{o}^{1.374} M_{a}^{0.343}}{C q h d_{m}^{0.618}}\right)^{1.16}
$$

So, $R_{a}$ is a function of all cutting parameters, which include abrasive factor, machinability number, water pressure, orifice diameter, abrasive flowrate, quality level index, target material thickness, mixing tube diameter. As only 80 mesh garnet has been used as abrasive particle in this test, and machinability for titanium alloy is a known number, and optimum abrasive flowrate has been used, $R_{a}$ could be assumed as a function of water pressure, orifice diameter, quality level index, target material thickness and mixing tube diameter. Except that, orifice diameter to mixing tube diameter ratio has been fixed as $1 / 3$ which has been verified by a lot of experiments and has been accepted extensively in abrasive water jet field, therefore, in order to simplify modeling process, there is no need to consider orifice diameter and mixing tube diameter as major affecting factors at the same time. that,

Based on the above analysis, it is reasonable to assume

$R_{a}=n_{0} P^{n_{1}} d_{f}^{n_{2}} q^{n_{3}} T^{n_{4}}$

Where:

$R_{a}:$ surface roughness $(\mu m)$

$P$ : Water pressure $(\mathrm{MPa})$

$T$ : Thickness of sample (mm) $d_{f}:$ Focusing tube diameter $(\mathrm{mm})$

$q$ : quality level index of cutting surface

$n_{0}, n_{1}, n_{2}, n_{3}, n_{4}:$ regression coefficients

So, by using regression analysis method, surface roughness models for both top side and bottom side can be gotten as following,

Top side model:

$$
R_{a_{\text {top }}}=\frac{33142.12 \times P^{0.1241} \times d_{f}^{0.4245}}{q^{0.2735} \times T^{0.2052}}
$$

Bottom side model:

$$
R_{\text {qotom }}=\frac{1216459 P^{0.8326} d_{f}^{0.742} T^{0.1324}}{q^{0.937}}
$$

\subsection{Verification of the Empirical Model with Cutting Experiments}

In order to verify the effectiveness of the model developed, another series of experiments have been carried out. In these series of experiments, all other parameters have been kept the same as previous tests. After tests, surface roughness has been measured and the results have been compared with values calculated from the developed model.

As shown in Figs. (24-27), values calculated from developed model matched well with actually measured values though some differences showed which might be caused by fitting error.

\section{CONCLUSIONS AND DISCUSSIONS}

Based on the above analysis, the following conclusions can be reached:

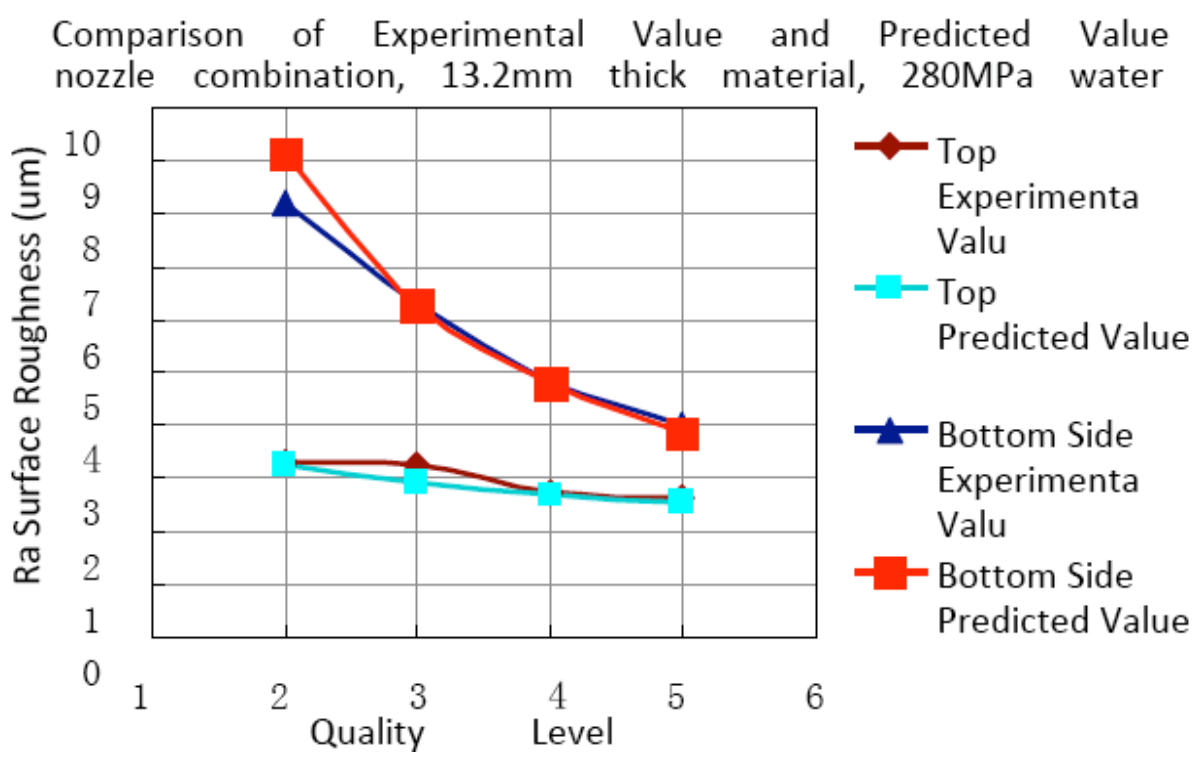

Fig. (24). Comparison of experimental value and predicted value $(0.35: 1.05 \mathrm{~mm}$ nozzle combination, $13.2 \mathrm{~mm}$ thick material, $280 \mathrm{MPa}$ water pressure). 
Comparison of Experimental Value and Predicted Value nozzle combination, $20.32 \mathrm{~mm}$ thick material, $280 \mathrm{MPa}$ Water

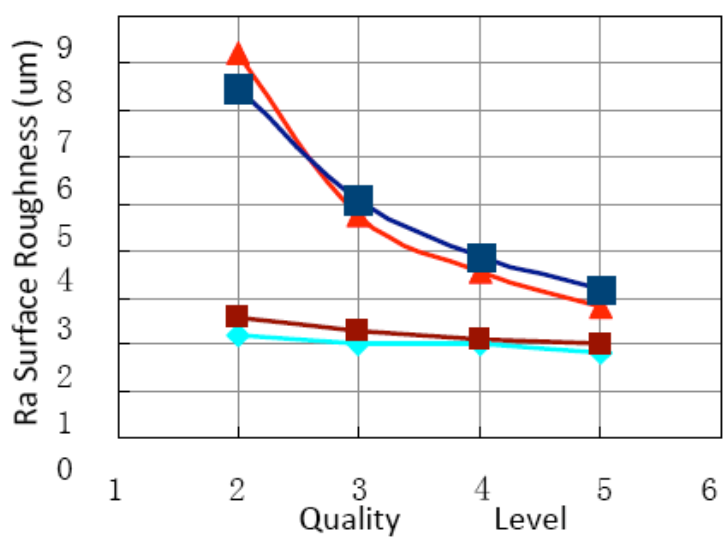

$\longrightarrow$ Top

Experimenta

Valu

$\rightarrow$ Top

Predicted Value

- - Bottom Side

Experimental

Valu

- Bottom Side

Predicted

Fig. (25). Comparison of experimental value and predicted value $(0.35: 1.05 \mathrm{~mm}$ nozzle combination, $20.32 \mathrm{~mm}$ thick material, $280 \mathrm{Mpa}$ water pressure).

Comparison of Experimental Value and Predicted Value nozzle combination, $13.2 \mathrm{~mm}$ thick material, 350MPa Water Pressure)

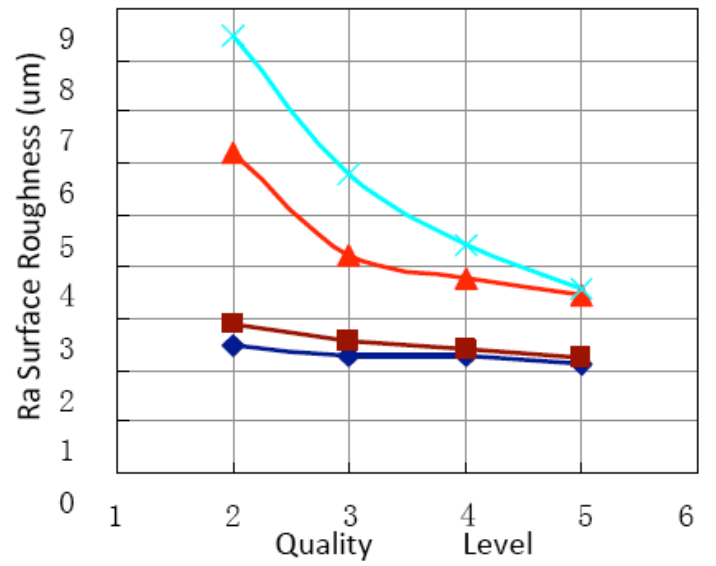

$\sim$ Top

Experimental

Valu

$\rightarrow-$ Top

Predicted

- Bottom Side

Experimenta

Valu

Bottom Side

Predicted

Fig. (26). Comparison of experimental value and predicted value $(0.25: 0.76 \mathrm{~mm}$ nozzle combination, $13.2 \mathrm{~mm}$ thick material, $350 \mathrm{Mpa}$ water pressure).

$$
\text { Comparison of Experimental Value and Predicted Value }
$$
nozzle combination, $20.32 \mathrm{~mm}$ thick material, 350MPa water pressure)

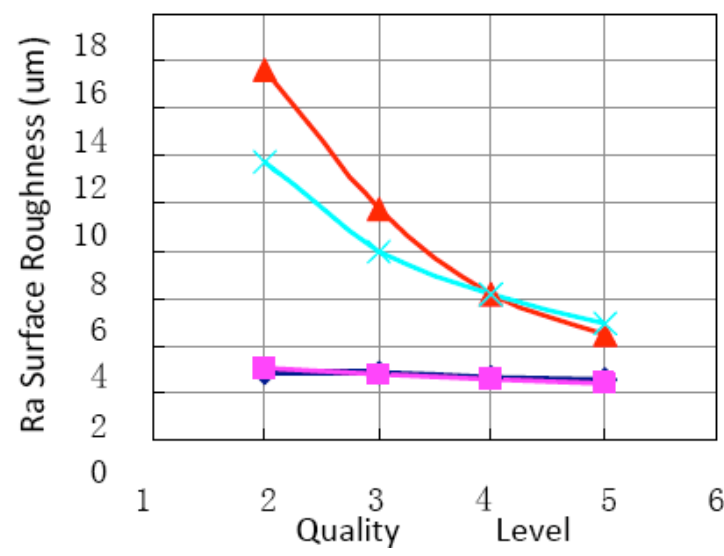

$\sim$ Top

Experimenta

Valu

- Top

Predicted

- Bottom Side

Experimenta

Valu

$\because$ Bottom Side

Predicted

Fig. (27). Comparison of experimental value and predicted value $(0.35: 1.05 \mathrm{~mm}$ nozzle combination, $20.32 \mathrm{~mm}$ thick material, $350 \mathrm{Mpa}$ water pressure).

(1) Vibration does exist in jet. However, the vibration of jet is not the major reason which cause striation marks presented on AWJ cutting surfaces.
(2) As long as the kinetic energy of the jet is not high enough to cut material away directly, step is formed. The step is then removed by following accumulated 
jet when its energy is high enough. However, the step removal process is not a stable material removal process, and rough cutting surface is expected during this process because the striation marks are expected.

(3) Striation marks can be removed by lowering the cutting speed, by which more abrasive particles impact on the same spot. In that case, material can be removed by direct cutting.

(4) Though AWJ cutting surface roughness is linearly correlated to cutting speed, actually, it is affected by cutting parameters indirectly since cutting speed is decided by all cutting parameters. Water pressure, quality level index, nozzle combination and target material thickness are factors which affect surface roughness on both top side and bottom side.

(5) On top side, surface roughness $\mathrm{Ra}$ is in the range of 2 to $5 \mu \mathrm{m}$, which means as long as cutting speed is low enough, surface roughness on the whole cutting interface can be controlled under $6.33 \mu \mathrm{m}$ which would satisfy many applications. On bottom side, $\mathrm{Ra}$ is in a big range between $3 \mu \mathrm{m}$ and $303 \mu \mathrm{m}$, therefore, it is important to select proper parameters in order to satisfy requirement.

(6) Based on experiments, empirical models for surface roughness prediction on both top side and bottom side have been built and verified.

\section{ACKNOWLEDGEMENTS}

This research was supported by the National Innovate Research Groups Foundation of China (50621403), Natural Science Foundation Project of CQ CSTC (2009BB4038) and Fundamental Research Funds for the Central Universities (CDJRC 10240007).

\section{REFERENCES}

[1] A. Chillman, M. Ramulu, "Observations of titanium surfaces impinged with ultra-high pressure waterjets", In: 2009 American WJTA Conference and Expo, Houston, Texas, 4-H. 2009.

[2] Available from: www.omax.com

[3] J. Zeng, J. Olsen and B. Guglielmetti, "Taper-free abrasive watejet cutting with a tilting head", In: 2005 WJTA American Waterjet Conference, Houston, Texas, 2005, Paper 7A-2.
[4] N.S. Guo, H. Louis and G. Meier, "Surface structure and kerf geometry in abrasive water jet cutting: formation and optimisation", In: Proceedings of the Seventh Water Jet Conference, dWJTA Seattle, Washington, 1993, pp. 1-25, vol. 1.

[5] J. Chao, E.S. Geskin and Y. Chung, "Investigation of the dynamics of the surfaces topography formation during abrasive waterjet machining", In: Proceedings of the 11th International Conference on Jet Cutting Technology, BHR Group St. Andrews, Scotland, Kluwer Academic Publishers, 1992, pp. 593-603.

[6] M. Monno and C. Ravasio, "The effect of cutting head vibration on the surfaces generated by waterjet cutting", Int. J. Mach. Tools Manuf. , vol. 45, pp. 355-363, 2005.

[7] F.L. Chen and E. Siores, "The effect of cutting jet variation on surface striation formation in abrasive water jet cutting", J. Mater. Process. Technol., vol. 135, pp. 1-5, 2003.

[8] D. Arola and M. Ramulu, "Mechanism of material removal in abrasive waterjet machining", In: Proceedings of the Seventh Water Jet Conference, WJTA Seattle, Washington, 1993, pp. 46-64, vol. 1.

[9] J. Zeng, and A. Henning, "Kerf Characterization in Abrasive Waterjet Cutting", In: 2009 American WJTA Conference \& Expo, Houston, Texas, 2009, Paper 1-H.

[10] H. Orbanic and M. Junkar, "Analysis of striation formation mechanism in abrasive water jet cutting", Wear, vol. 265, Issues 56, pp. 821-830, 2008.

[11] A. W. Momber, and R. Kovacevic, "Principles of Abrasive Water Jet Machining", p. 217, 1997.

[12] P. J. Singh, W. Chen, and J. Munoz, "Comprehensive evaluation of abrasive waterjet cut surface quality", In: Proc. 6th American Waterjet Conference, Houston, USA, 1991, p. 139.

[13] H. Blickwedel, and N. S. Guo, and H. Haferkamp, "Prediction of abrasive jet cutting performance and quality", Jet Cutting Technol., Elsevier, London, 1991, pp. 163.

[14] N. S. Guo, H. Louis, and G. Meier, "Surface structure and kerf geometry in abrasive waterjet cutting: formation and optimization", In: Proc. 7th American Waterjet Conference, Seattle, USA, 1993, p. 1.

[15] G. Lutjering, and J. C. Williams, "Titanium, Springer-Verlag", Berlin, Heidelberg, 2003.

[16] E. O. Ezugwu, and Z. M. Wang, "Titanium alloys and their machinability - a review", J. Mater. Processing Technol., Vol. 68, pp. s262, 1997.

[17] S. Zhang, Z. Liao, and D. Chen, "Accurate titanium machining using abrasive water jet", In: 9th Pacific Rim International Conference on Water Jetting Technology, Japan, 2009, pp. 87.

[18] S. Zhang, X. Li, and Y. Gu, "Optimum abrasive flow rate modeling for titanium alloy cutting using abrasive water jet", Int. J. Abrasive Technol., vol. 2, no. 4, p. 400, 2009.

[19] J. Zeng, "Mechanisms of Brittle Material Erosion Associated with High Pressure AWJ Processing - A Modeling and Application Study", Dissertation, University of Rhode Island, Rhode Island, America, 1992. 